\title{
Outcomes of Surgery and Craniospinal Radiotherapy for Adult Patients with Medulloblastoma
}

\author{
Zeliha GÜZELÖZ, Zümre ARICAN ALICIKUŞ, Oğuz ÇETINAYAK, Fadime AKMAN
}

Department of Radiation Oncology, Dokuz Eylül University Faculty of Medicine, İzmir-Turkey

\begin{abstract}
OBJECTIVE
The aim of the present study was to evaluate treatment outcomes for adult patients with medulloblastoma who received craniospinal irradiation following surgery at Dokuz Eylül University Radiation Oncology Department.
\end{abstract}

\begin{abstract}
METHODS
Twelve patients were evaluated retrospectively. Median age was 31 years (range: $18-55$ years). According to Chang staging system, 3 (25\%) of the patients were T1, 2 (17\%) were T2, $5(42 \%)$ were T3, and $1(8 \%)$ was T4; 1 patient could not be staged due to inadequate preoperative imaging. Tumor location, stage, presence of residual disease, duration between surgery and radiotherapy (RT), age, and sex were evaluated as prognostic factors. Statistical analyses were conducted using Kaplan-Meier method and SPSS for Windows, Version 15.0 (SPSS Inc., Chicago, IL, USA).
\end{abstract}

\section{RESULTS}

Median dose was 36 Gy (range: 32-44 Gy) to craniospinal field and 54 Gy (range: 50-56 Gy) to primary tumor location. Median follow-up time was 62 months (range: 4-212 months). Five-, 10-, and 15-year overall survival rates were $79 \%, 63 \%$, and 63\%, and 5-, 10- and 15-year progression-free survival rates were $63 \%, 63 \%$, and $63 \%$, respectively. No statistically significant prognostic factor was found for survival rate. Three (25\%) patients developed serious hematological toxicity during RT course. No grade 3 or 4 late side effect was observed.

\section{CONCLUSION}

Despite the limited number of cases, results are consistent with the literature. Evaluation of features of this rare disease requires studies with larger number of.

Keywords: Craniospinal; medulloblastoma; radiotherapy.

Copyright $\odot$ 2017, Turkish Society for Radiation Oncology

\section{Introduction}

Medulloblastoma is one of the primitive neuroectodermal tumors (PNET) that derive from the ectodermal layer.[1] It is one of the rare tumors of central nervous system tumors in adults. It is most frequently seen between ages $20-40$. The incidence has been reported as
0.5/100.000.[2-4] The most common histological type is desmoplastic neuroblastoma. Gross total resection is recommended for all cases without diffuse disease. The standard therapeutic approach is craniospinal radiotherapy (RT) initiating one month after the surgery.[5]

According to current literature, 5 year survival rates in adult patients with medulloblastoma (MB) range 
between $63 \%$ and $84 \%$.[6] The most important factors that effect survival are age, type of resection (total-subtotal-biopsy), presence residual tumor and malignant cells in cerebrospinal fluid (CSF).[7]

In this study, treatment outcomes for adult patients with medulloblastoma who received craniospinal irradiation following surgery in Dokuz Eylül University Radiation Oncology Department were evaluated retrospectively.

\section{Materials and Methods}

\section{Patients, diagnosis and staging}

In our study, 12 patients who received craniospinal RT following surgery (subtotal/ gross total resection) were evaluated. Median age was 31 (18-55), and female/ male ratio was $1 / 3$.

Seven patients had preoperative magnetic resonance imaging (MRI). Tumor location was cerebellar in $8(67 \%)$ patients, vermis in $3(25 \%)$ patients, supratentorial in $1(8 \%)$ patient. Supratentorial tumor was projecting toward sylvian fissure from left temporal region.

Gross total resection was performed in $10(83 \%)$ patients, and subtotal resection was performed in $2 \mathrm{pa}-$ tients; residual tumor was detected in 6 patients (50\%) at postoperative MRI. According to Chang staging system, $3(25 \%)$ of the patients were T1, $2(17 \%)$ were T2, $5(42 \%)$ were T3, and 1 (8\%) was T4; 1 patient could not be staged due to inadequate preoperative imaging. All patient were diagnosed with medulloblastoma in pathological examination, and desmoplastic medulloblastoma was identified in 3 of the patients. While cerebrospinal fluid examination could not be performed in 2 patients, no malignant cells were detected in the CSF of the remaining 10 patients (Table 1).

Postoperative neurological performance scores[8] were 3 in $3(25 \%)$ patients, 2 in $1(8 \%)$ patient, 1 in 8 (67\%) patients. Karnofsky Performance Scores were 60 in $2(17 \%)$ patients, 70 in $1(8 \%)$ patient, 80 in $2(17 \%)$ patients, and 90 in the remaining 7 (58\%) patients.

\section{Radiotherapy}

All patients were immobilized at prone position using forehead-chin rest and orfit head mask during radiotherapy. Craniospinal RT was performed in opposite parallel two lateral cranial and two different spinal fields (dorsal and lumbosacral) with appropriate photon energy levels (6-18 MVX, Co-60), followed by opposite parallel boost at posterior fossa. Planned doses were 36 Gy (1.8-2 Gy/fraction, 5 fractions/week) at cranial and spinal fields, and $54 \mathrm{~Gy}$ at posterior fossa.

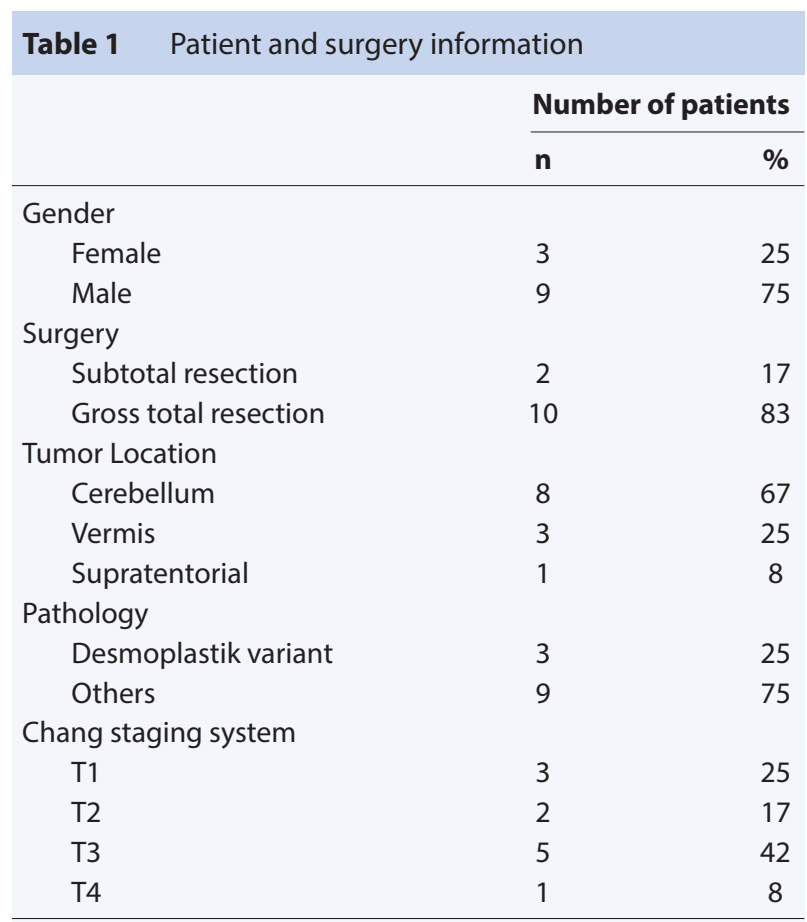

\section{Statistical analysis}

Statistical analyses were carried out with Kaplan-Meier method using SPSS-15 software. Tumor location, stage, presence of residual disease, duration between surgery and RT, age, and sex were evaluated as prognostic factors. Overall survival was calculated as the time beginning from the diagnosis until the last follow-up or death; progression-free survival was calculated as the time beginning from diagnosis until progression.

\section{Results}

Median duration between surgery and RT in patients who applied for RT was 38 (20-220) days. Median follow-up duration was 64 (4-212) months. Fraction doses at cranial and spinal fields ranged between 1.8-3.6 Gy (median is $1.8 \mathrm{~Gy}$ ); total median doses were 36 (32-40) Gy at cranial field, 54 (50-56) Gy at primary tumor location, and 36 (32.4-44) Gy at spinal field. One patient with supratentorial tumor received adjuvant chemotherapy (CT). Five, 10, and 15-year overall survival rates were $79 \%, 63 \%$, and $63 \%$, and 5, 10 and 15 -year progression-free survival rates were $63 \%, 63 \%$, and $63 \%$, respectively (Figure 1,2). Recurrence was detected in 3 $(25 \%)$ patients at $39^{\text {th }}, 47^{\text {th }}$, and $57^{\text {th }}$ months. These patients were treated with CT, surgery, and surgery+ CT, respectively. The patient who was treated with surgery died 2 months after recurrence because of sepsis that 


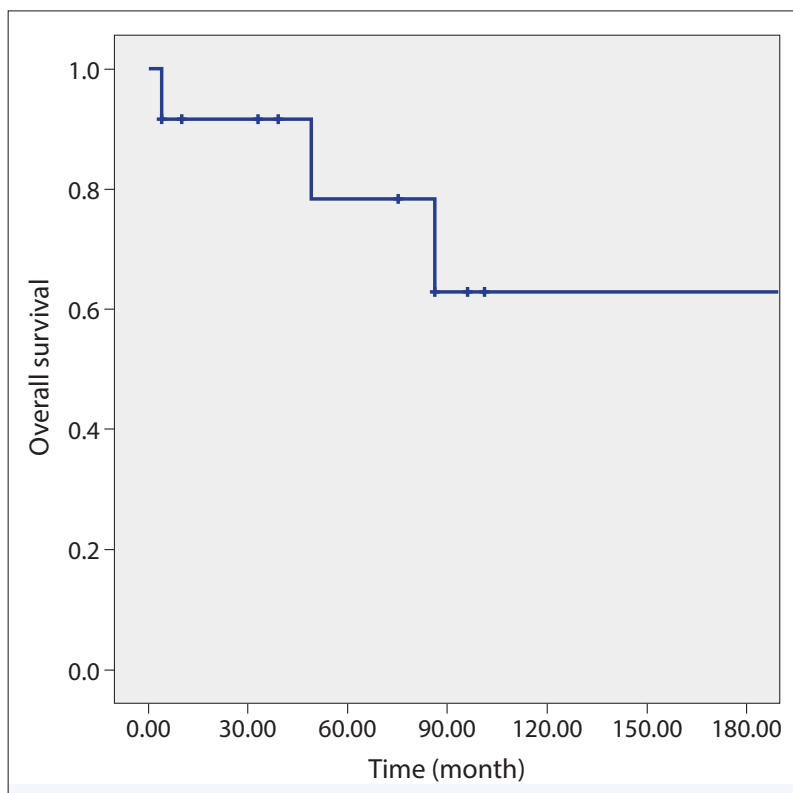

Fig. 1. Overall survival table.

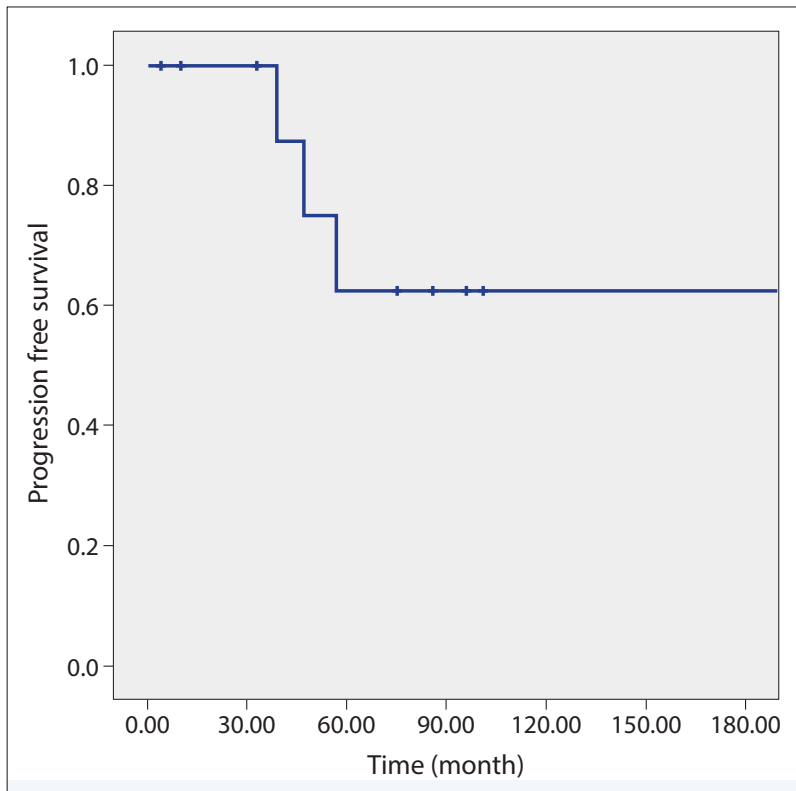

Fig. 2. Progression free survival table.

developed at early period. The patient who was treated with CT+surgery died 26 months after recurrence. The patient who was treated with CT was followed up for 35 months after recurrence without any problems. Due to limited number of patients, a statistically significant prognostic factor effecting the survival rates could not be determined. Three (25\%) patients developed severe acute hematological toxicity during RT; none of the patients developed late grade 3-4 side effects.

\section{Discussion}

MB occurs most commonly in childhood (median age is 6).[9] It is one of the rare tumors of central nervous system in adults. The tumor is located at the posterior fossa. Craniospinal involvement is observed as in the rates of $30-35 \%$.[9] MRI or computed tomography is used for diagnosis. MRI is preferred because of its superiority for demonstrating the relation to neighboring tissues and diffusion of the tumor.[10] In our study, craniospinal MRI was performed in 7 patients for this reason. Gross total resection is recommended for all patients without diffuse disease. Type of resection, residual amount, cerebrospinal fluid involvement are prognostic factors. While patients who had complete or near complete resection, who had residual tumor smaller than $1.5 \mathrm{~cm}^{2}$, and who do not have CSF involvement are regarded to have standard risk, those who had subtotal resection or biopsy, who had residual tumor larger than $1.5 \mathrm{~cm}^{2}$, and who have CSF involvement are regarded to have high risk. [7] In our retrospective study, images of some patients could not be obtained; therefore, risk assessment could not be made.

In adjuvant RT, our clinical target volume covers whole craniospinal axis. Craniospinal RT is a difficult treatment modality making use of complex techniques. Since craniospinal axis containing the brain, spinal cord, and meningeal structures, which are defined as clinical target volume, have an irregular structure, technical difficulties arise during planning phase.[9] Craniospinal axis is irradiated with 36 Gy in high risk patients. Then, it is recommended to increase the dose to $54-55.8 \mathrm{~Gy}$ at posterior fossa. In case of intracranial or spinal metastasis, the dose should be increased to 45-50 Gy in spinal metastasis and to 50-54 Gy for cranial metastasis. [11] In our study, median doses were 36 (32-40) Gy at cranial field, 54 (50-56) Gy at primary tumor location, and 36 (32.4-44) Gy at spinal field, similar to other reports in literature.

With the advances in technology, intensity modulated radiotherapy and volumetric modulated arc treatment have been shown to be superior to three dimensional conformal therapy for the treatment of $\mathrm{MB}$ today, due to more homogenous doses at target volume and lower dosage to organ at risk.[12,13] It is reported that heart, inner and middle ear, temporal lobe doses are lower in proton treatment which is known to be a more advanced technique, compared to treatments with photons and electrons.[14,15]

Germanwala et al. reported that boost dose at posterior fossa in the presence of residual tumor could be 
performed with gamma knife. There were less side effects, and higher doses could be attained by this way. [16] There has been a dose deduction in standard risk patients in order to decrease long-term morbidity related to RT. There are studies suggesting that spinal dose could be deduced to 23.4 Gy in low risk pediatric patients with $\mathrm{MB}$; however, this concept is controversial for adult group of patients.[17] In one study by Packer et al., pediatric patients with standard risk were administered weekly vincristine concurrently with 24.3 Gy irradiation at craniospinal field, and dose at posterior fossa was completed to 55.8 Gy with boost. Five year progression-free survival in these patients who received adjuvant vincristine, CCNU, cysplatine CT was determined as 79\%.[18] In the series of Carrie and Padovani, adult patients were administered concurrent chemo-RT. In Carrie's study involving 30 patients, 7 patients were administered CCNU-vincristine concurrently with RT. Five and 10 year overall survival rates were reported as $58.5 \%$ and $41 \%$, respectively.[19]

Adjuvant RT should be initiated within 28-30 days following surgery, and the treatment should be continued without any interruptions if possible. In International Society of Paediatric Oncology (SIOP) PNET-3 study, it was stated that interruptions during treatment affected overall and disease-free survival adversely.[20] In their study involving adult patients with $\mathrm{MB}$, Abacioğlu et al. reported the median duration of interval between surgery and RT as 31 (12-69) days. Five year disease-free survival rates were found as $0 \%$ for patients who started their treatment earlier than 3 weeks, $85 \%$ for patients who started their treatment between 3 to 6 weeks, and $75 \%$ for patients who started their treatment after 6 weeks.[21] In our study, the median duration to initiate RT after surgery was 38 (20-220) days. Any statistically significant effect of this duration on survival rates could not be analyzed due to limited number of patients in our study. In 3 patients who had progression, the duration between surgery and RT was 25, 47 and 39 days. It is known that the administered adjuvant CT contributes to survival in pediatric patients with $\mathrm{MB}$ who have adverse prognostic factors.[22] The importance of adjuvant CT for adult $\mathrm{MB}$ cases is controversial. CT does not have any contribution on survival in low risk patients. Moreover, adult patients do not show good tolerance against pediatric CT regimes.[23] In their study involving 32 patients, Herrlinger et al. found that adjuvant vincristine, CCNU, cisplatin or methotrexate, cisplatin chemotherapies contributed to survival, although it was not statistically significant. [24] In our study, adjuvant CT was administered in one patient with supratentorial tumor. There was no recurrence or distant metastasis in the follow-up after adjuvant RT or CT.

Recurrences develop mostly in posterior fossa. [23-25] A review of recurrence patterns indicated that recurrences occur mostly within 2 years in pediatric group. $[26,27]$ This duration is longer for adult patients. Chan et al. reported median duration before recurrence as 26 months. It was stated that $29 \%$ of the recurrences occurred 5 years after treatment.[25] In our study, recurrence was detected in 3 patients at $39^{\text {th }}, 47^{\text {th }}$, and $57^{\text {th }}$ months, found at the primary tumor location. Those patients died at $2^{\text {nd }}$ and $26^{\text {th }}$ months after recurrence. Durations before recurrence in our patients were longer than the durations reported in the literature. Systemic involvement is seen in 5\% of patients. Most frequently bone and bone marrow involvements are observed.[28] In our patients, no distant metastasis was detected.

According to evaluation of all patients in our study, 5,10 , and 15 year overall survival rates were $79 \%, 63 \%$, and $63 \%$, respectively; 5,10 , and 15 year progressionfree survival rates were $63 \%, 63 \%$, and $63 \%$, respectively. These results are in conformity with the results reported in literature. According to a report published in 2012 by Lai et al., which reviewed 13 studies, 5 and 10 year general survival rates varied between $63-84 \%$, and $52-73 \%$, respectively; 5 year progression-free survival rates varied between $62-80 \%$. [6] In those studies where median follow-up durations ranged between 3.5 to 6.6 years, there were no results for 15 year survival rates.

Age is an important prognostic factor for childhood MB. However, it is not regarded as an important parameter for adult age group; moreover, there is evidence that increasing age is favorable with regard to survival.[29] It is thought that adult women with MB have better survival outcomes. Lee et al. determined the 5 year survival rate as $92 \%$ for females and $40 \%$ for males.[29] In our study, age and sex factors were not found significant with regard to survival.

Most of the studies did not yield a statistically significant prognostic factor. In the study by Padovani et al. which had the greatest number of patients, metastasis, postoperative performance, central nervous system involvement were determined as factors that are important for prognosis; [19] other prognostic factors were determined to be $\mathrm{M}$ stage and duration before initiation of postoperative RT in the study by Abacioglu et al.[21] location of tumor in the study by Menon et al.[30] type of surgery, RT and histology in the study by Lai et al.[31] gender in the study by Riffaud et al.[32] 
In our study, we think we could not find a statistically significant prognostic factor because of the limited number of patients.

There are studies reporting that the biological markers, TrkC and C-MYC are independent predictive factors for medulloblastoma and primitive neuroectodermal tumors.[33,34] MDM2 overexpression is thought to be associated with shorter survival.[35] However, we could not evaluate these parameters in our study, since these biological markers are not routinely tested in our center.

Because adult $\mathrm{MB}$ is a rare pathology, studies in literature include limited number of patients and are retrospective. Although surgery and craniospinal RT is the standard treatment, its importance in adult $\mathrm{MB}$ is still controversial. As a conclusion, despite the limited number of cases in our study, our results are in conformity with other results in literature. However, in order to clarify prognostic properties and effectiveness of adjuvant treatments such as CT in this rare disease, studies including larger number of patients are required where cases would be collected at multiple centers.

\section{Disclosure Statement}

The authors declare no conflicts of interest.

\section{References}

1. Merchant TE. Central nervus system tumors in children. In: Leonard L. Gunderson, Joel E. Tepper editors. Gunderson \&Tepper Clinical Radiation Oncology, $2^{\text {nd }}$ edition. Philadelphia. Elsevier Churchill Livingstone; 2007. p. 1576.

2. Carrie C, Lasset C, Blay JY, Négrier S, Bouffet E, Barbet $\mathrm{N}$, et al. Medulloblastoma in adults: survival and prognostic factors. Radiother Oncol 1993;29(3):3017.

3. www.CBTRUS.org. Statistical report: Primary brain tumors in the United States, 1998-2002 Central Brain Tumor Registry of the United States 2005.

4. www.cbtns.org/reports/reports.html June 14, 2006.

5. Malika LS, Donahue BR, Vogelbaum MA, Tome WA, Gilbert MR, Mehta MP. Primary intracranial neoplasms. In: Halperin EC, Brady LW, Perez CA, editors . Perez and Brady's Principles and Practise of Radiation Oncology, 5 th edition. Philadelphia: Lippincott Williams \& Wilkins; 2008. p. 741.

6. Lai SF, Wang CW, Chen YH, Lan KH, Cheng JC, Cheng AL, et al. Medulloblastoma in adults. Treatment outcome, relapse patterns, and prognostic factors. Strahlenther Onkol 2012;188(10):878-86.
7. Chang CH, Housepian EM, Herbert C Jr. An operative staging system and a megavoltage radiotherapeutic technic for cerebellar medulloblastomas. Radiology 1969;93(6):1351-9.

8. Winger MJ, Macdonald DR, Cairncross JG: Supratentorial anaplastic gliomas in adults: The prognostic importance of extent of resection and prior low-grade glioma. J Neurosurg 1989;71(4):487-93.

9. Freeman CR, Freeman JP, Taylor RE. Central Nervus System Tumors in Children. In: Halperin EC, Brady LW, Perez CA, editors. Perez and Brady's Principles and Practise of Radiation Oncology, 5 th edition. Philadelphia: p. 1836-8.

10. Packer RJ, Rorke-Adams LB, Lau CC, et al. Embryonal and pineal region tumors. In: Pizzo PA, Poplack DG, editor Principles and Practice of Pediatric Oncology. 6th ed. Philadelphia. Lippincott Williams and Wilkins 2011. p. 772-808.

11. Miralbell R, Fitzgerald TJ, Laurie F, Kessel S, Glicksman A, Friedman HS, et al..Int J Radiat Oncol Biol Radiotherapy in pediatric medulloblastoma: quality assessment of Pediatric Oncology Group Trial 9031. Phys 2006;64(5):1325-30.

12. Kusters JM, Louwe RJ, van Kollenburg PG, KunzeBusch MC, Gidding CE, van Lindert EJ, et al. Optimal normal tissue sparing in craniospinal axis irradiation using IMRT with daily intrafractionally modulated junction(s). Int J Radiat Oncol Biol Phys 2011;81(5):1405-14.

13. Lee YK, Brooks CJ, Bedford JL, Warrington AP, Saran FH. Development and evaluation of multiple isocentric volumetric modulated arc therapy technique for craniospinal axis radiotherapy planning. Int J Radiat Oncol Biol Phys 2012;82(2):1006-12.

14. Lee CT, Bilton SD, Famiglietti RM, Riley BA, Mahajan A, Chang EL, et al. Treatment planning with protons for pediatric retinoblastoma, medulloblastoma, and pelvic sarcoma: how do protons compare with other conformal techniques? Int J Radiat Oncol Biol Phys 2005;63(2):362-72.

15. Lin R, Hug EB, Schaefer RA, Miller DW, Slater JM, Slater JD. Conformal proton radiation therapy of the posterior fossa: a study comparing protons with three-dimensional planned photons in limiting dose to auditory structures. Int J Radiat Oncol Biol Phys 2000;48(4):1219-26.

16. Germanwala AV, Mai JC, Tomycz ND, Niranjan A, Flickinger JC, Kondziolka D, et al. Boost Gamma Knife surgery during multimodality management of adult medulloblastoma. J Neurosurg 2008;108(2):2049.

17. Oyharcabal-Bourden V, Kalifa C, Gentet JC, Frappaz D, Edan C, Chastagner P, et al. Standard-risk medullo- 
blastoma treated by adjuvant chemotherapy followed by reduced-dose craniospinal radiation therapy: a French Society of Pediatric Oncology Study. J Clin Oncol 2005;23(21):4726-34.

18. Packer RJ, Goldwein J, Nicholson HS, Vezina LG, Allen JC, Ris MD, et al. Treatment of children with medulloblastomas with reduced-dose craniospinal radiation therapy and adjuvant chemotherapy: A Children's Cancer Group Study. J Clin Oncol 1999;17(7):212736.

19. Padovani L, Sunyach MP, Perol D, Mercier C, Alapetite C, Haie-Meder C, et al Common strategy for adult and pediatric medulloblastoma: a multicenter series of 253 adults. Int J Radiat Oncol Biol Phys 2007;68(2):43340.

20. Taylor RE, Bailey CC, Robinson KJ, Weston CL, Ellison D, Ironside J, et al. United Kingdom Children's Cancer Study Group Brain Tumour Committee; International Society of Paediatric Oncology.Impact of radiotherapy parameters on outcome in the International Society of Paediatric Oncology/United Kingdom Children's Cancer Study Group PNET-3 study of preradiotherapy chemotherapy for M0-M1 medulloblastoma. Int J Radiat Oncol Biol Phys 2004;58:1184-93.

21. Abacioglu U, Uzel O, Sengoz M, Turkan S, Ober A. Medulloblastoma in adults: treatment results and prognostic factors Int J Radiat Oncol Biol Phys 2002;54(3):855-60.

22. Packer RJ, Sutton LN, Elterman R. Outcome for children with medulloblastoma treated with radiation and cisplatin, CCNU, and vincristine chemotherapy. J Neurosurg 1994;81(5):690-8.

23. Kunschner LJ, Kuttesch J, Hess K, Yung WK. Survival and recurrence factors in adult medulloblastoma: the M.D. Anderson Cancer Center experience from 1978 to 1998. Neuro Oncol 2001;3(3):167-73.

24. Herrlinger U, Steinbrecher A, Rieger J, Hau P, Kortmann RD, Meyermann R, et al. Adult medulloblastoma: prognostic factors and response to therapy at diagnosis and at relapse. J Neurol 2005;252(3):291-9.
25. Chan AW, Tarbell NJ, Black PM, Louis DN, Frosch MP, Ancukiewicz M, et al. Adult medulloblastoma: prognostic factors and patterns of relapse. Neurosurgery 2000;47(3):623-32.

26. Bloom HJ. Medulloblastoma: prognosis and prospects. Int J Radiat Oncol Biol Phys 1977;2(9-10):1031-3.

27. Prados MD, Warnick RE, Wara WM, Larson DA, Lamborn K, Wilson CB. Medulloblastoma in adults. Int J Radiat Oncol Biol Phys 1995;32(4):1145-52.

28. Berger MS, Baumeister B, Geyer JR, Milstein J, Kanev PM, LeRoux PD. The risks of metastases from shunting in children with primary central nervous system tumors. J Neurosurg 1991;74(6):872-7.

29. Le QT, Weil MD, Wara WM, Lamborn KR, Prados MD, Edwards MS, et al. Adult medulloblastoma: an analysis of survival and prognostic factors. Cancer J Sci Am 1997;3(4):238-45.

30. Menon G, Krishnakumar K, Nair S. Adult medulloblastoma: clinical profile and treatment results of 18 patients. J Clin Neurosci 2008;15(2):122-6.

31. Lai R. Survival of patients with adult medulloblastoma: a population-based study. Cancer 2008;112(7):156874.

32. Riffaud L, Saikali S, Leray E, Hamlat A, Haegelen C, Vauleon E, et al. Survival and prognostic factors in a series of adults with medulloblastomas. J Neurosurg 2009;111(3):478-87.

33. Grotzer MA, Hogarty MD, Janss AJ, Liu X, Zhao $H$, Eggert A, et al. MYC messenger RNA expression predicts survival outcome in childhood primitive neuroectodermal tumor/medulloblastoma. Clin Cancer Res 2001;7(8):2425-33.

34. Grotzer MA, Janss AJ, Fung K, Biegel JA, Sutton LN, Rorke LB, et al. TrkC expression predicts good clinical outcome in primitive neuroectodermal brain tumors. J Clin Oncol 2000;18(5):1027-35.

35. Giordana MT, Duó D, Gasverde S, Trevisan E, Boghi A, Morra I, et al. MDM2 overexpression is associated with short survival in adults with medulloblastoma. Neuro Oncol 2002;4(2):115-22. 